\title{
Blended Scaffolding Strategies through Facebook to Aid Learning and Improving the Writing Process and Writing Performance
}

\author{
${ }^{1}$ Abdul Hameed Abdul Majid, ${ }^{2}$ Siti Hamin Stapa, ${ }^{3}$ Yuen Chee Keong \\ ${ }^{1,3}$ (School of Language Studies \& Linguistics, Faculty of Social Sciences \& Humanities, Universiti Kebangsaan \\ Malaysia)
}

\begin{abstract}
Learners today anticipate learning content to include some form of blended instruction that encourages either formal or informal collaboration in discovery oriented tasks. This study hinges on the sociocultural theory and the zone of proximal development (Vygotsky 1978) and Holton and Clarks (2006) scaffolding strategies. The study begins with a semi-structured interview given to 10 purposively selected participants from both experimental and control groups at the onset of the study to ascertain their perceptions about using blended scaffolding strategies through Facebook to aid learning and in improving the writing process and writing performance. The study continues for 14 weeks beginning with a pre-test for both groups. The experimental group i.e. the group using blended scaffolding strategies go through classroom teaching with the aid of computer technology and scaffolding using Facebook after school hours. The control group only goes through chalk and talk instruction. A post-test is administered at the end of 14 weeks to determine the effects of the treatment on the experimental group. Initial findings through the semi-structured interview regarding perceptions about using blended scaffolding strategies through Facebook to aid learning and in improving the writing process and writing performance favours the blended scaffolding strategies as a learning method compared to mere chalk and talk strategy.
\end{abstract}

Keywords - blended scaffolding strategies, Facebook, technology use, writing process, writing performance

\section{Introduction}

Writing has been propagated to be one of the most arduous language skills learners are expected to master (Yah Awang Nik et.al 2010). Despite spending many years developing their writing skills, most second language learners (L2) of English are confronted with obstacles in their endeavour. These obstacles among others are due to the complexities of the writing skill (Celce-Murcia 2001). Writing, which is a complex and continuous process is further made difficult for the L2 learner due to sociological, sociocultural, linguistic and cognitive factors (White and Arndt 1991).

In order to assuage writing difficulties faced by L2 learners, this current study adopted Holton and Clark's (2006) scaffolding strategies in a blended learning (face-to-face and online) class to investigate if students' writing performance could be enhanced. Scaffolding is a term used for the process of assisting a person to carry out a task that is unfamiliar or beyond his/her ability. Through the scaffolding process, learners are helped to carry out parts of tasks within their ability, and the adult scaffolds the rest.

In their theory of scaffolding, Holton and Clarke (2006) differentiate scaffolding into two aspects. The first is termed as domain and the next is agency. They further divide domain into two categories which are conceptual scaffolding and heuristic scaffolding. Scaffolding by the teacher to provide conceptual understanding and development is called conceptual scaffolding and scaffolding provided to find ways to solve a problem in learning is termed heuristic scaffolding. They go on suggesting that in terms of agency, three types of scaffoldings are involved: expert, reciprocal and self-scaffolding. The Scaffolds provided by a teacher is expert scaffolding. On the other hand, a scaffold provided by a student working in a group either face-to-face or online is reciprocal scaffolding and finally self-scaffolding is when a learner is in a situation where he or she is able to scaffold his/her own self. These three types of agency scaffolds (expert, reciprocal and self-scaffolding) are used in the blended scaffolding strategies through Facebook in this study.

\section{Objective of the Study}

The objective of this study is to investigate how ESL students perceive the use of blended scaffolding strategies through Facebook for learning and in improving the writing process and writing performance.

\section{Literature review}

Scaffolding is a term used for the process of assisting a person to carry out a task that is unfamiliar or beyond his/her ability. In the scaffolding process, learners are encouraged to carry out parts of tasks that are within their ability. Tasks that are not within their ability are filled or scaffolded by an adult. 
The scaffolding process entails molding the learners' interest and limiting their choices. It is also geared towards maintaining their goal orientation, highlighting essential aspects of the task, controlling their disappointment, and displaying activity paths for them (Wood, Bruner, Ross, 1976). This concept of scaffolding propagated by Wood et. al. is germinated from Vygotsky's concept of the Zone of Proximal Development (henceforth, ZPD). Vygotsky (1978: 86) defines ZPD as:

Those functions that have not yet matured but are in the process of maturation, functions that will mature tomorrow but are currently in an embryonic state. These functions could be termed 'buds' or 'flowers' of development rather than 'fruits' of development.

\section{Blended Learning as Scaffold to Online Learning}

Whether as a vehicle for writing or other learning areas, online learning has been noted to be beneficial for learning. The potential of a blended learning is exerted by Victoria (2011). She mentions that educators and learners are provided with new information and communication technologies (ICTs) learning environment that stimulate and enhance the teaching and learning process. In relation to this, Victoria points that new educational concepts such as blended learning are being developed and blended learning has a positive effect in minimizing dropout rates and in improving students' grades.

In further explaining blended learning, (Rossett, Douglis, \& Frazee, 2003) mention that blended learning integrates or blends learning programs in different formats to achieve a common goal. Most of the time, blended learning programs merge traditional classroom and online activities. A blended learning program might present materials needed for the lesson earlier through an asynchronous web-based program, then teach newer content of the curriculum in a classroom. Additionally, blended learning can also integrate materials in other formats.

\section{Scaffolding Writing Through Online Learning}

Online learning is an emerging field (Conole \& Oliver 2007). Therefore, different terminologies are subscribed to illustrate it. The terms used are also often argued upon. Many terms and definitions have mushroomed describing online learning. Among others, they are Web-Based Training, Internet-Based Training, Advanced Distributed Learning, e-Learning, Computer Mediated Communication, Computer Supported Collaborative Learning and Distance Learning (Beaudoin 2006).

The merits of online tools for scaffolding writing are mentioned by Demetriadis, Papadopoulos, Stamelos and Fisher (2007). They state that online scaffolding has been shown by research to positively affect students' achievement. Online scaffolding too, has a great potential for developing conceptual understanding (Zydney 2008). Further exposition on the merits of online scaffolding is made by Englebert, Wu and Zhao (2005). They stress that writing improvement is brought about by online scaffolding. Supyan Hussin (2008) too affirms the benefits of online learning in improving language proficiency saying online learning positively improves language proficiency.

Numerous other researches too, point to the fact that human beings approach formal education backed by a variety of schemata or prior knowledge, beliefs, skills and concepts. These beliefs, prior knowledge and concepts greatly influence how one views the world and how one remembers, reasons, and solves problems, and acquire new knowledge (Bransford, Brown and Cocking 2000).

Scaffolding is a teaching strategy that is laden with the notion that learners confront an educational setting with a great deal of prior knowledge. Some of this knowledge may not be accurate, but the important point is the process of building on what a student already knows thus making scaffolding an effective instructional technique (Byrnes 2001).

\section{Social Networking Sites as Learning Tools to Scaffold Writing}

Liu (2010) contends that Web 2.0 technologies are able to transform education in general and foreign language learning in particular. Furthermore, they are giving new opportunities for developing different online learning environments and enhancing interactivity. These opportunities and interactivities in return enhance participation and feedback between students, their peer groups and teachers.

One of the social networking sites belonging to the Web. 2.0 Technology is Facebook. Facebook is a social networking site which can be utilized as an educational technology tool that facilitates online communications between second language learners and their friends. In relation to this, Madge et. al. (2009) characterizes Facebook as providing the 'social glue' in helping students to settle into university life. At the same time, (Sebastián Valenzuela2, Namsu Park3, and Kerk F. Kee4 2008) have mentioned that sites like Facebook allow them to discuss issues and exchange both public and private news.

Facebook is currently considered the most popular platform for online social networking among university students. It is also considered the latest example of communication technologies that have been widely-adopted by students. Additionally, Facebook has the potential to become a valuable resource to support their educational communications and collaborations with faculty (Liu 2010). 
A study by Haverback (2009) on Facebook made positive observations on students' creation and participation in an online learning community. Students were found to discuss assignments, ask and answer questions, post information, and support one another for their Reading Education Methods course constructively. Similarly Roblyer et al. (2010) revealed that university students are very open to the possibility of using Facebook and similar technologies to reinforce in and out of classroom work. Through Facebook, learners are able to communicate with and between friends in class, give comments on topics being discussed and give feedback on published essays either synchronously or asynchronously. Participants are also able to share links to tutoring programs or other Internet resources that may be useful in helping their writing process (Haverback 2009).

Since the craze for social networking sites such as Facebook, My Space and Twitter is a phenomenon among netizens the world over these days (Nadzrah Abu Bakar 2010), and in view of the benefits it gives as a scaffolding tool for writing, this paper investigates how ESL students perceive the use of blended scaffolding strategies through Facebook for learning and in improving the writing process and writing performance.

\section{Methodology}

This study which was carried out at a Malaysian rural secondary school examined the effects of blended scaffolding strategies through Facebook on ESL Learners' writing performance. The participants were 16 year old ESL learners of mixed ethnicity and gender. It employed a mixed method design. The quantitative method in this study encompassed a convenience sampling where the researcher selected participants because of willingness and ability to be studied. The design of the study was a quasi-experimental pretest-posttest experimental and control group design with 45 participants in each group. The experimental group went through blended scaffolding strategies through Facebook for writing and the control group went through traditional classroom teaching. Scores from a pre and post writing test from the experimental and control groups formed the quantitative data in this study. The qualitative data was collected by analyzing the essays written by participants in both the experimental and control groups. A content analysis was performed to see improvements in their composition. Interviews from a selected number of participants in the experimental and control group was also carried out at the onset of the study in view of gauging how participants of the study perceived the use of social networking site to help them in their learning, the writing process and writing performance.10 participants who were purposively selected from 90 participants of the study were interviewed using a semistructured interview. The interview transcripts were coded by chronologically ordering them first. The data then was read several times. Coding was performed by generating several category codes as responses were read and labeled. The transcripts were line numbered and coded. The comments were color coded according to categories and subcategories in relation to the research question.

\section{Findings}

From the interview data gathered and analyzed, four major themes emerged. They are:

i. Participants' preference on their preferred learning strategy.

ii. How blended scaffolding strategies will help them for learning?

iii. How blended scaffolding strategies would help their writing process?

iv. How blended scaffolding strategies would help their writing performance?

Examples of learners' verbatim responses:

1. Participant's preference on their preferred learning strategy

P.1.E: Arr...is better to use both arr.. both chalk and talk and also with technology like ICT arr...Arr...because if teacher use social networking at home we can also ask about something we don't know.

P.2.E: Pretty much I'll say it's good use. I prefer both chalk and talk and use technology. Pretty much I'll say social networking has a bad reputation...If the teacher started using it for teaching...arr...it will be awesome...and students will more likely know that Facebook can also be used for knowledge and a a...education. So, pretty much I support the use of ICT in class

P.3.E: Arr...bothlah chalk and talk and technology like computer ar..Facebook...ar ...ICT. Because it's interesting and not boring. Hm...

P.4.E: Both. Arr... chalk and talk and technology like internet and Facebook...arr...computer. Arr...because it is interesting and I can arr.. I can... I'm not feel bored.

P.5.E: I prefer the teacher use the both. Chalk and talk and the technology. Nowadays the teenager more attracted by the technology.

2. How blended scaffolding strategies will help them for learning?

P.1.E: Arr.. arr...oh..we can send arr...an essay using ...to him and told him to check the essay for error. 
P.2.E: I think it'll be great because when teacher use internet and stuff, it means that when we are studying it is not within the school only. If I am not mistaken, school only covers about 5-6 hours of our daily life right? So ...so if teachers began to use Facebook for studying purposes then it will be like we have more time to study. Say for some students with low self-esteem, they won't ask the teachers in class. Students are not shy to ask their friends right? So they can use Facebook to ask friends or teacher during chat. Em.. it's pretty much you and your teacher. Not to be shy...

P.3.E: Ar...I can ask the question that arr... I didn't know and... Ar...get clarification.

P.4.E: I can ask my teacher after the school about the arr..subject. I can arr... arr... Yes...I can get clarification.

P.5.E: If I don't know the question,...so I ask to my teacher solution for that. So my teacher give solution for that. Because after school hours we can communicate with teachers because it will help me keep in touch even after school hours.

\section{How blended scaffolding strategies would help their writing process?}

P.1.E: Arrr... Yes. Arr yes. Arr...at home we also can chat with teacher about the topic or the subject... I can ask teacher how to get idea ...ar..and arr... edit.

P.2.E: I'm pretty sure ya..it will help my writing process. Because em...like I said just now, at times you tend to forget. tend... something and sometimes even the simple spelling at times if you are asking your friends for example like if you gonna ask your friend ..he might feel a low self-esteem common an easy word. Even if you gonna ask your teacher in class. you gonna feel shy. If you gonna ask how to spell 'what' are you serious you donno how to spell 'what'? something like that. We tend to forget and we tend to miss spell the word.

P.3.E: Maybe... Em ...yes. Em ...teach how to use suitable vocabulary, help me to edit and generate ideas.

P.4.E: Yes. Arr...arr...it help me to edit my work...get more idea... write more clearly.

P.5.E: Ya. It will be improved. I can generate ideas from my teachers. I can correct my vocabulary...I can edit my essay and so on. I also can revise what I discuss with my teacher. Of course I can improve my writing performance because...I am a shy person. I can ask one to one to my teacher.

\section{How blended scaffolding strategies would help their writing performance?}

P1.E: Arr...I can also get better mark for writing. Arr... write more better.

P2.E: Facebook will help to practice writing, spelling and improve writing. It will help a lot to expand my ideas, get points. It will help me get higher marks and write well.

P.3.E: Arr... I can improve my grades.

P.4.E: Yes. I also can improve my writing grade....performance.

P5.E: I can improve my mark in my examination.

\section{Discussion}

The analyses of interview data from all the participants were in tandem in their preference of the learning strategy. They preferred learning writing using both the ordinary classroom chalk and talk together with technology. They preferred the blended scaffolding strategy because through the use of technology such as internet, Facebook and other ICT tools, they are able to bring more fun and help for learning writing beyond the walls of the classroom and make learning possible out of normal class time; anywhere and anytime. Additionally, all the participants also conjured that the use of blended scaffolding strategies helped them in learning. Several reasons were cited on how they got help from the blended scaffolding strategies. Among the reasons cited were they could get help from peers and their teacher after school hours and not having to wait for normal school time. They were also able to keep up with school work even if they had to miss school on a particular day and the blended scaffolding strategies using Facebook helped them to overcome their shyness of asking questions in class.

The interview too, revealed that blended scaffolding strategies helped their writing process. The participants mentioned that blended scaffolding strategies enabled them to generate ideas, edit their work, and improve their vocabulary and spelling. Not only that, they were also able to get help with the use of idioms and grammar. Finally, all the participants mentioned that blended scaffolding strategies through Facebook would help their writing performance. They agreed that the use of blended scaffolding strategies through Facebook would help them get better grades for their writing because of the help they get from the learning activities carried out through Facebook.

\section{Conclusion}

The findings of this study about the perceptions of participants in using blended scaffolding strategies through Facebook for learning and in improving the writing process and writing performance have provided evidence on the learning preference of students. Students of these days prefer teachers to give them something more than the ordinary chalk and talk. They look forward to the use of technology such as internet, Facebook 
and other ICT tools which enables them to have fun and help them learn writing beyond the walls of the classroom. Through the use of ICT, Internet and the social networking sites such as Facebook, they are able to learn not only within the class time but anywhere and anytime. Furthermore, Web 2.0 technologies are offering new opportunities for developing different online learning environments and enhance interactivity. This in return, promotes participation and feedback between students, their peer groups and teachers. Finally, the use of blended scaffolding strategies in learning is perhaps one of the most viable solutions that can accommodate both group and individualized learning. Additionally, the use of blended scaffolding strategies in learning can enhance social interactions among learners and facilitate L2 writing process and later improve writing.

\section{References}

[1] A.N. Yah, S. Badariah, W.C. Muhammad, Y. Kamaruzzaman and R.H. Hasif , The writing performance of undergraduates in University of Technology Mara, Terengganu Malaysia. Journal of Languages and Culture, 1(1), 2010, 8-14.

[2] M. Celce-Murcia, Teaching English as a second or foreign language (3rd. Ed.,. (Boston: Heinle \& Heinle, 2001).

[3] R. White, \& V. Arndt, V, Process Writing, (London: Longman, 1991).

[4] D. Holton., \& D. Clarke, Scaffolding and metacognition. International Journal of Mathematical Education in Science and Technology, 37(20), 2006, 127-143.

[5] D. Wood, J. Bruner, \& G. Ross, The role of tutoring in problem solving, Journal Of Psychology and Psychiatry, 17, 1976, 89-100.

[6] L.S. Vygotsky, Mind in Society: The development of higher psychological process. (Cambridge, MA: Harvard University Press, 1978).

[7] M. Victoria López-Pérez, M. Carmen Pérez-López, .and Lázaro Rodríguez-Ariza, Blended learning in higher education: Students' perceptions and their relation to outcomes. Computers \& Education, 56, (3),2011, 818-826.

[8] A. Rosselt, F. Douglis, \& R.V. Frazee, Strategies for Building Blended Learning.(Online) http://www.learningcircuits.org/2003/jul2003/rosset.htm [15 Julai 2010]

[9] G. Conole, M. Oliver, I. Falconer, A. Littlejohn \& J. Harvey, . Designing for learning. In G. Conole \&

[10] M.F. Beaudoin, Perspectives on Higher education in the digital age ( New York: Nova Science Publishers, 2006).

[11] S.N. Demetriadis, P.M. Papadopoulos, I.G. Stamalos, \& F. Fischer, The effects of Scaffolding students' context-generating cognitive activity in technology-enhanced Case-based learning. Computers \& Education, 51(2), 2007, 939-954.

[12] J.M. Zydney, Cognitive tools for scaffolding students defining an ill structured Problem., Journal of Educational Computing Research, 38 (4), 2008, 353-385.

[13] C.S. Englert, X. Wu., \& Y. Zhao, Cognitive tool for writing: Scaffolding the Performance of students through technology. Learning Disabilities Research \& Practice, 20(2),2005, 184-198.

[14] H. Supyan, Creating a Bigger ZPD for ESL Learners Via Online Forum, ABR \& TLC Conference Proceeding, Orlando, Florida, USA, 2008. 1-9.

[15] J. Bransford, A, Brown, \& R. Cocking, How People Learn: Brain, Mind, and Experience \& School. (Washington, DC: National Academy Press, 2000).

[16] B. Byrnes, Cognitive Development and Learning in Instructional Contexts 2nd Ed.. ( Needham Heights, M.A.: Allyn and Bacon, 2001).

[17] Y. Liu, Social media tools as a learning resource. Journal of Educational Technology Development and Exchange, 3(1),2010, 101114.

[18] C. Madge, J. Meek, J. Wellens, \& T. Hooley, Facebook, social integration and informal learning at university: "It is more for socialising and talking to friends about work than for actually doing work". Learning, Media and Technology, 34(2),2009, 141 155 .

[19] Sebastián Valenzuela2, Namsu Park3, and Kerk F. Kee4. 2008. Lessons from Facebook: The Effect of Social Network Sites on College Students' Social Capital. (University of Texas at Austin, 2008).

[20] Haverback, H. 2009. Facebook: Uncharted territory in a reading education classroom, Reading Today, 27(2), 2009.

[21] M.D. Roblyer, M. McDaniel, M. Webb, J. Herman, \& J.V. Witty, Findings on Facebook in Higher Education: A Comparison of College Faculty and Student Uses and Perceptions of Social Networking Sites. The Internet and Higher Education, 13(3), 2010 134140.

[22] A.B. Nadzrah, L. Hafizah \& Y. Azizah, ESL students feedback on the use of blogs for language teaching. 3L The Southeast Asian Journal of English Language Studies, 16(1), 2010 120-141. 